\title{
Enhanced propagation of adult human renal epithelial progenitor cells to improve cell sourcing for tissue-engineered therapeutic devices for renal diseases
}

\author{
Angela J. Westover ${ }^{1 *}$, Deborah A. Buffington ${ }^{1}$ and H. D. Humes ${ }^{1,2,3}$ \\ ${ }^{1}$ Innovative BioTherapies Inc., Ann Arbor, MI, USA \\ ${ }^{2}$ Internal Medicine, University of Michigan, Ann Arbor, MI, USA \\ ${ }^{3}$ CytoPherix Inc., Ann Arbor, MI, USA
}

\begin{abstract}
Renal cell therapy employing cells derived from adult renal epithelial cell (REC) progenitors promises to reduce the morbidity of patients with renal insufficiency due to acute renal failure and end stage renal disease. To this end, tissue engineered devices addressing the neglected biologic component of renal replacement therapy are being developed. Because human donor tissue is limited, novel enhanced progenitor cell propagation (EP) techniques have been developed and applied to adult human kidney transplant discards from six donors. Changes include more efficient digestion and the amplification of progenitors prior to terminal epithelial differentiation promoted by contact inhibition and the addition of retinoic acid. Differentiated morphology in EP populations was demonstrated by the ability to form polarized epithelium with tight junctions, apical central cilia and expression of brush border membrane enzymes. Evaluation of lipopolysaccharide stimulated interleukin-8 secretion and $\gamma$-glutamyl transpeptisade activity in EP derived cells was used to confirm therapeutic equivalence to REC obtained using published techniques, which have previously shown efficacy in large animal models and clinical trials. Yield exceeded $10^{16}$ cells/gram cortex from the only kidney obtained due to an anatomical defect, while the average yield from diseased kidneys ranged from $1.1 \times 10^{9}$ to $8.8 \times 10^{11}$ cells/gram cortex, representing an increase of more than 10 doublings over standard methods. Application of the EP protocol to REC expansion has solved the problem of cell sourcing as the limiting factor to the manufacture of cell based therapies targeting renal diseases and may provide a method for autologous device fabrication from core kidney biopsies. Copyright (C) 2012 John Wiley \& Sons, Ltd.
\end{abstract}

Received 11 October 2010; Revised 13 May 2011; Accepted 5 July 2011

Supporting information may be found in the online version of this article.

Keywords kidney; adult stem cells; tissue expansion; tissue engineering; renal insufficiency

\section{Introduction}

Acute renal failure (ARF) and chronic renal disease (CRD) are distinctly different disease processes and current therapy for both disorders is suboptimal. ARF arises from toxic or ischaemic (usually simultaneous) tubule damage from antibiotics, chemotherapeutic agents or shock

*Correspondence to: A. J. Westover, Innovative Biotherapies, 401 West Morgan Road, Ann Arbor, MI 48108, USA. E-mail: awestover@innbio.com; website:www.innbio.com during infectious or major operative procedures. The development of ARF in a hospitalized patient results in a five- to eight-fold higher risk of death (Humes, 1995; Chertow et al., 1998; Bates et al., 2001), with overall mortality rates exceeding 50\%. However, if the patient survives the episode of ARF, the regenerative repair processes within the kidney can result in a return of kidney function in $90-95 \%$ of patients with this acute disorder. The cause of death in patients with acute renal failure is usually the development of Systemic Inflammatory Response Syndrome (SIRS), with resulting cardiovascular 
collapse, ischaemic damage to vital organs and multiple organ failure (MOF) (Humes, 2000; Humes et al., 2002). The propensity of patients with ARF to develop SIRS and sepsis suggests that renal metabolic function, specifically renal tubule cell function secondary to Acute Tubular Necrosis (ATN), plays a critical immunomodulatory role in individuals under stress states. This function is not replaced with standard dialysis therapy.

Unlike ARF, CRD is an irreversible process of progressive kidney damage, commonly from diabetes and hypertension, which leads to end-stage renal disease (ESRD). Patients with ESRD on dialysis continue to have major medical, social and economic problems with life expectancies of only 4-5 years (Iglehart, 1993; Xue et al., 2001; Cukor et al., 2007). While the ideal standard for kidney replacement therapy for ESRD remains organ transplant, with less than ten thousand kidney transplants completed each year and the current number of patients awaiting transplantation approaching sixty thousand (Collins et al., 2005), the need far exceeds availability. For all disease processes, available renal replacement therapies consisting of haemofiltration, haemodialysis or chronic ambulatory peritoneal dialysis are non-physiological and fail to address the homeostatic, regulatory, metabolic and endocrine functions of the kidney. Patients with ESRD are at high risk for cardiovascular and infectious diseases, despite conventional renal replacement therapy. A recent clinical trial failed to show survival benefit from increased doses of dialysis above the current standard of care (Humes, 1995), suggesting that there are important metabolic derangements not adequately treated with conventional dialytic treatment. Survival of renal transplant recipients far exceeds that of age-, sexand risk-matched controls awaiting transplant, clearly demonstrative of the metabolic function provided by the kidney beyond filtration. ESRD currently affects over 430000 US patients and has an annual cost of more than $\$ 25$ billion, and patient numbers are predicted to increase to 2.24 million by 2030 (Schrier and Wang, 2004).

The potential success of renal cell therapy lies in the growing appreciation that most disease processes are not due to the lack of a single protein, but develop due to alterations in complex interactions of a variety of cell products. The renal tubule cell's roles in glutathione reclamation, glutathione peroxidase synthesis and activation of vitamin D3, with its important immunoregulatory functions, are well-recognized pathways to maintain important tissue integrity and host defence under stress conditions (Humes, 2000; Humes et al., 2002). A less recognized role of the kidney, chiefly the renal tubule, is its potential immunoregulatory function. The kidney is derived embryologically from dorsal mesoderm, a collection of cells also important in the development of bone marrow stem cells (Turpen and Knudson, 1982; Saxen, 1987). The maturation of cells responsible for erythropoietin synthesis and activation of $1,25-(\mathrm{OH})_{2}$ vitamin D3 in the kidney is reflective of this embryonic origin. Phylogenetically, in bony fish and amphibians without lymph systems, the kidney is the major antibodyproducing organ (Smith et al., 1967; Zapata, 1979; Turpen and Knudson, 1982). Not surprisingly, mammalian renal proximal tubule cells are immunologically active. They are antigen-presenting cells (Bishop et al., 1988; Wuthrich et al., 1990) that possess co-stimulatory molecules (Wahl et al., 2002) and that synthesize and process a variety of inflammatory cytokines (Prodjosudjadi et al., 1995; Leonard et al., 1999; van Kooten et al., 1999).

The development of renal epithelial cell (REC) therapy to replace the endocrine and immunological functions of the kidney, in addition to haemofiltration, promises to add significant value to the current suboptimal treatments of renal failure. Candidate biological markers that are known to be dysregulated in ESRD correlate with poor outcome and are linked to known mechanisms of disease, include markers of inflammation and oxidative stress.

A methodology to isolate and grow REC from adult human kidneys has already been developed (Smith et al., 2006) and the described methods used to provide the renal cell component of tissue-engineered devices evaluated in large animal and clinical studies (Tumlin et al., 2008). However, using standard cell-processing techniques, RECs isolated from human transplant discards do not have the expansion capability required to provide cell therapy for the large patient population suffering from ARF and ESRD. The ability to differentiate a totipotent embryonic stem cell down an intricately orchestrated kidney-specific path is still in its infancy and does not provide a timely solution to cell sourcing for renal replacement therapy. Clinical and experimental observations suggest that REC progenitor cells have immense proliferative potential, as evidenced by complete

Table 1. Comparison of standard vs. enhanced propagation protocols

\begin{tabular}{|c|c|c|}
\hline Step & Standard method & Enhanced propagation \\
\hline Enzymatic digestion & Collagenase $<600 \mu \mathrm{M}$ particle size & Liberase/Blendzyme. Single cell $\rightarrow 212 \mu \mathrm{M}$ particle size \\
\hline Centrifugation & $50 \mathrm{~g}$ (exclusive) & $300 \mathrm{~g}$ (inclusive) \\
\hline Plating density & $500 \mu \mathrm{l}$ pellet $/ 100 \mathrm{~mm}$ plate & $4-32 \mu \mathrm{l}$ pellet $/ 100 \mathrm{~mm}$ plate \\
\hline Media change & $\begin{array}{l}24 \mathrm{~h} \text { post-plating, non-adherent cells } \\
\text { removed by aspiration }\end{array}$ & 7 days post-plating, non-adherent cells retained \\
\hline Matrix & Collagen IV/adsorbed FCS & Endogenous matrix \\
\hline Subculture & $\begin{array}{l}\sim 1 \times 10^{7} \text { cells seeded and } 2 \times 10^{7} \\
\text { recovered per T75 flask. Pass ratio } 1: 2\end{array}$ & $\begin{array}{l}1.25 \times 10^{6} \text { cells plated and } 2 \times 10^{7} \text { cells recovered } \\
\text { per T75 flask. Pass ratio } \sim 1: 16\end{array}$ \\
\hline Differentiation factor retinoic acid & $\begin{array}{l}\text { Added prior to primary passage. Cells } \\
\text { remain differentiated through passages }\end{array}$ & $\begin{array}{l}\text { Signals the end of precursor amplification. Added } \\
\text { on device or test well after confluence (contact } \\
\text { inhibition) }\end{array}$ \\
\hline
\end{tabular}


tubule regeneration to reform a fully functional and differentiated epithelium after severe nephrotoxic or ischaemic injury (Duffield and Bonventre, 2005). This regeneration potential has been attributed to haematopoetic or mesenchymal stem cells, rather than resident renal progenitor cells, with controversial results (Poulsom et al., 2001; Gupta et al., 2002; Kale et al., 2003). The most pertinent observation from these studies was that injection of mesenchymal stem cells following ischaemic injury enhances the regenerative potential and recovery of tubules, occurring without actual incorporation of these cells into the regenerated tubules, possibly due to a paracrine effect (Bi et al., 2007; Imai and Iwatani, 2007).

Current opinion is that precursors responsible for the repopulation of tubules reside within the kidney, possibly maintained within a specialized niche (Al-Awqati and Oliver, 2006; Sagrinati et al., 2006), although the defining characteristics and mechanism are still under investigation (Duffield and Bonventre, 2005; Al-Awqati and Oliver, 2006; Challen et al., 2006). Regardless of source, these resident kidney progenitor cells have stem cell-like characteristics, with a high capacity for self-renewal and the ability to differentiate under defined conditions into mature somatic cells, as evidenced by tubule regeneration (Hall and Watt, 1989; Potten and Loeffler, 1990). An approach to more closely mimic the in vivo environment promises to greatly enhance REC propagation potential and is the basis of these studies.

\section{Materials and methods}

\subsection{Tissue procurement}

Human cadaver kidneys, rejected for organ transplantation due to anatomical or fibrotic defects, were procured from the National Disease Research Interchange (NDRI). Additional donor acceptance criteria included: adults $<80$ years of age, blood tests negative for adventitious viruses, nonseptic, normal creatinine and blood urea nitrogen levels, no other indices of kidney disease, and time between cross-clamp and the beginning of tissue processing $\leq 36 \mathrm{~h}$. Tissue from six donors was simultaneously processed using enhanced propagation (EP) and the standard protocol. The method modifications are highlighted in Table 1.

\subsection{Cell isolation}

Kidneys were dissected clean of all external tissue, the capsule removed, the cortex cut from the medulla and the cortex weight documented. Finely minced cortex was digested at $1 \mathrm{~g}$ tissue/ml prewarmed enzyme (collagenase for the standard protocol or Liberase for EP)/DNase (0.239 Wunchst units and $250 \mathrm{Kunitz}$ units $/ \mathrm{ml}$ ) at $37^{\circ} \mathrm{C}$ for $20 \mathrm{~min}$ cycles. Using the standard protocol, the digestion was quenched with cold Dulbecco's modified Eagle's medium (DMEM) and all tissue aggregates $>850 \mu \mathrm{m}$ were returned to the digestion flask and the cycles repeated. The quenched slurry was subsequently sieved without further enzymatic digestion and remaining tissue aggregates $>600$ $\mu \mathrm{m}$ were discarded. For EP, the enzymatic digestion proceeded uninterrupted with only the $<212 \mu \mathrm{m}$ sieved filtrate being quenched as it passed into the collection beaker containing cold DMEM. To evaluate the relationship of aggregate and cell yield, EP slurry was further fractionated by differential sieving into 150-212, 90-150, 38-90 and $<38 \mu \mathrm{m}$ fractions. For the standard method, the tissue was washed by centrifugation at $50 \times g$ to preferentially retain intact tubules, while EP tissue was centrifuged at $300 \times g$, which was inclusive of single cells and aggregates that may have contained damaged and therefore more buoyant tubules.

\subsection{Primary plating}

RECs were cultured in UltraMDCK medium (UM, Lonza) supplemented with half the manufacturer's recommended dilution for insulin, transferrin, ethanolamine and selenium supplement (ITES; Lonza), $60 \mathrm{ng} / \mathrm{l}$ epidermal growth factor (hrEGF; R\&D Systems), $10^{-9} \mathrm{M}$ triiodothyronine and $1 \times$ penicillin-streptomycin. Standard plating density was $1 \mathrm{ml}$ $50 \times g$ pellet $/ 24 \mathrm{ml}$ medium $(20 \mathrm{ml} / \mathrm{T} 75$ flask $)$, and the non-adherent fraction was aspirated as a result of the first medium change after $24 \mathrm{~h}$ in culture. For EP plating, the cells were further diluted $1: 16$ by suspending $1 \mathrm{ml}$ of the $300 \times g$ pellet $/ 384 \mathrm{ml}$ medium $(20 \mathrm{ml} / \mathrm{T} 75$ flask). For three donors, initial plating density was evaluated over a wide range by continued 1:2 dilution until 1:516 dilution was achieved. Partial medium changes (50\%) were performed on an as-needed basis, with need assessed by monitoring glucose (Stanbio), lactate (Van Den Hamer and Elias, 1958; Krieg et al., 1967) and $\mathrm{pH}$ of the culture medium. Non-adherent cells were retained from primary EP culture through the first passage.

For both methods, subculture was accomplished as follows: cells were rinsed free of divalent cations, enzymatically released from plates using 0.05\% trypsinversene (Lonza) by incubation for $20 \mathrm{~min}$ at room temperature, and the reaction inhibited by $0.1 \% \mathrm{w} / \mathrm{v}$ soybean trypsin inhibitor (Gibco). Upon reaching tight confluence, retinoic acid (RA) was added to standard cultures $24 \mathrm{~h}$ before the first passage and cultures passed at 1:2, thus maintaining confluency in the range 50-100\%. Enhanced propagation cultures did not receive $\mathrm{RA}$ at confluence and were subcultured at $10^{5}$ cells $/ \mathrm{ml}, 12 \mathrm{ml} / 100 \mathrm{~mm}$ plate, and passaged when 50-75\% confluent, maintaining confluency in the range $6.25-75 \%$. For both standard and EP cultures, RA was added to the medium just prior to use, at a concentration of $10^{-7} \mathrm{M}$.

\subsection{Assessment of identity and function}

Tests were made on increasingly passaged EP cultures, while those generated using standard protocols were tested at the fifth passage, the point at which standard populations were integrated into devices for clinical studies. For all tests, EP cells were seeded at confluent density, $10^{6}$ cells $/ \mathrm{ml} /$ 
$5 \mathrm{~cm}^{2}$. RA was added after 2 days and the cells cultured for an additional 5 days prior to testing. For cytokine evaluation, the cell medium was supplemented with $0.1 \%$ bovine serum albumin, both with and without $10 \mu \mathrm{g} / \mathrm{ml}$ lipopolysaccharide (LPS); the supernatants were removed at $24 \mathrm{~h}$, clarified by centrifugation and the concentration of IL-8 determined by ELISA (R\&D Systems). A quantitative $\gamma$-glutamyl transpepsidase ( $\gamma \mathrm{GT}$ ) enzyme assay was developed using $\gamma$-glutamy-p-nitoanalide, a commercially available, $\gamma$ GT-specific colorometrc substrate (Stanbio) (Szasz, 1974). Activity was assayed in whole cell lysates prepared using a non-ionic detergent buffer and normalized with protein concentration (BioRad). One unit of activity is defined as the conversion of $1 \mu \mathrm{M}$ reagent $/ \mathrm{min} / \mathrm{mg}$ protein at $37^{\circ} \mathrm{C}$. For immunohistochemistry (IHC), cells were fixed in $4 \%$ paraformaldehyde, permeated with $0.1 \%$ Triton
$\mathrm{X}-100$ and subsequently labelled with antibodies to RECspecific markers, including acetylated tubulin (AT1; Zymed), zona occludens-1 (ZO1; Zymed), $\gamma$ GT (Lab Vision) and aminopeptidase-N (APN; Becton Dickinson), and the nuclei labelled with 4',6-diamidino-2-phenylindole dihydrochloride (DAPI).

\subsection{Cryopreservation}

Trypsinized cells were mixed at $10^{7}$ cells/ml in cryoprotectant medium (10\% DMSO in UM), placed in a controlled-rate freezing apparatus (Nalgene, Mr. Frosty) at $-80^{\circ} \mathrm{C}$ overnight and then transferred to the vapour phase of liquid nitrogen. The cells remained frozen for at least 2 weeks prior to use in cryopreservation studies. a

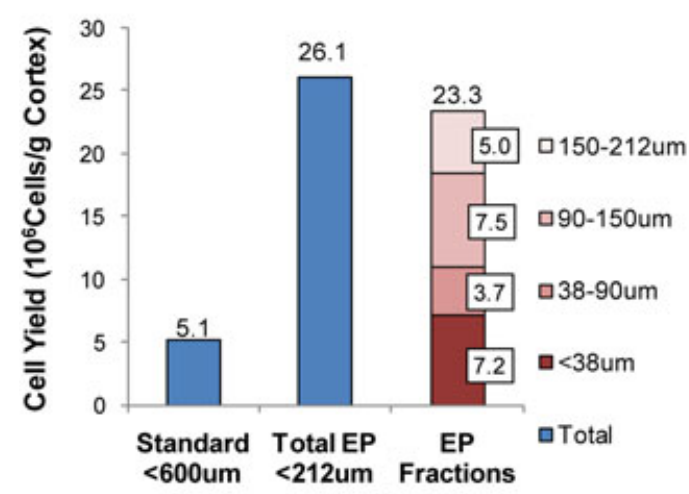

c b

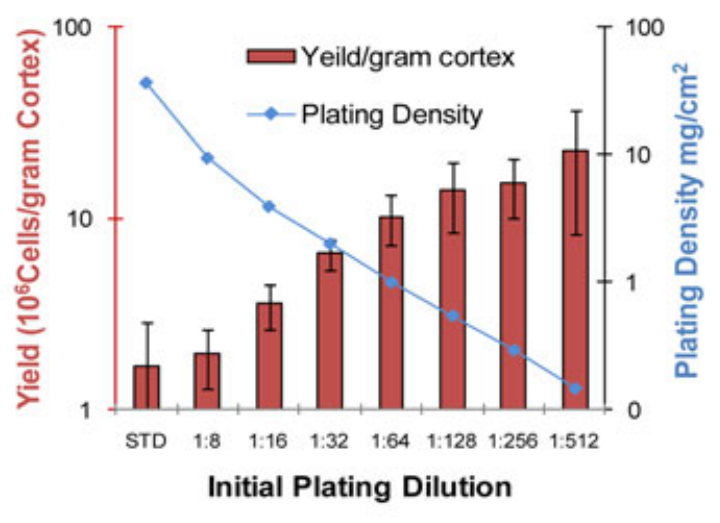

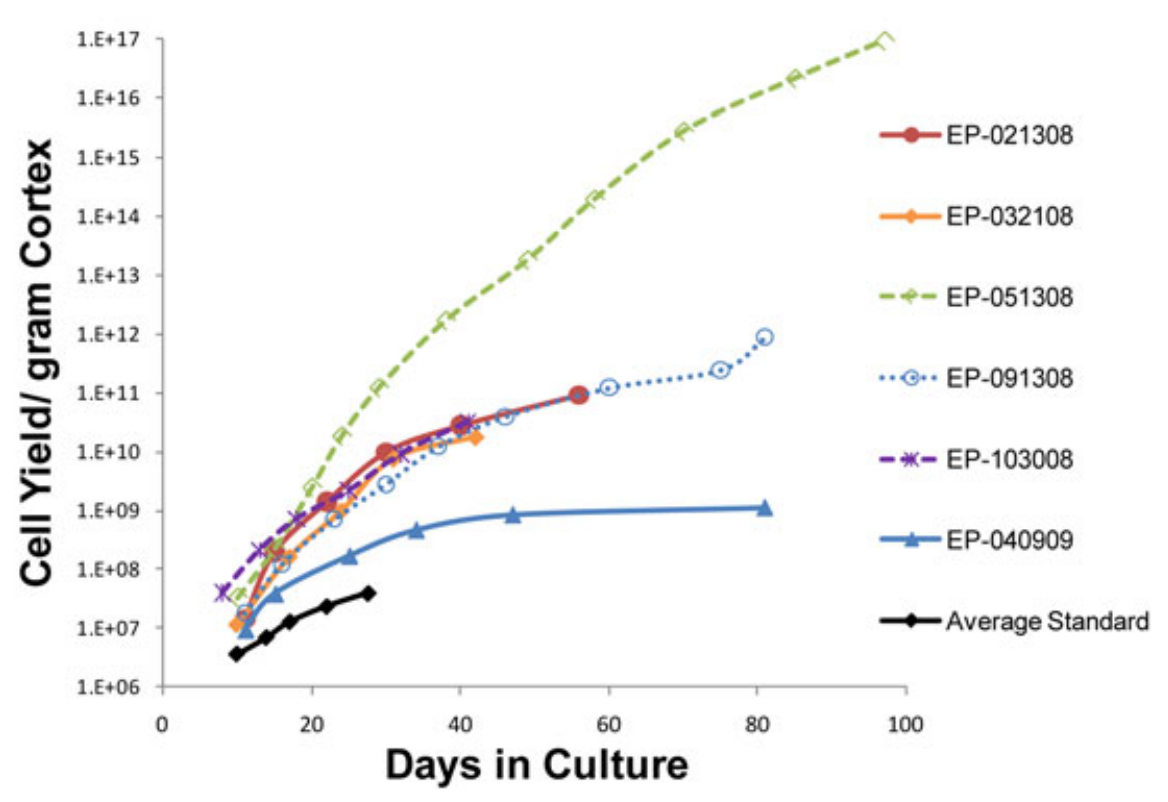

Figure 1. Cell yield calculations. Application of the enhanced propagation (EP) protocol for the isolation and propagation of renal epithelial progenitor cells to human cadaver kidneys greatly increased yield. (a) Yield increase is observed at the first passage. Progenitor cells are present in all sieved cell fractions, shown by fraction (red) far right, including the $<38 \mu \mathrm{m}$ portion, in which any 3D stem cell niche would be destroyed. Representative results from the 13 September 2008 isolate are shown. (B) Cell yield/g cortex was proportional to dilution factor at primary plating. The results shown are average \pm SE for $n=3$ isolates. (C) The growth curves of six individual EP isolates and the average standard are plotted as total cell number through time. Although growth potential varies greatly between isolates, the plots clearly demonstrate that a far greater cell mass was obtainable using EP techniques; note the logarithmic scale displayed on the vertical axis (cell yield/g cortex). In (A, B) primary yield is defined as the number of cells resulting from the initial plating, counted post-trypsinization prior to subculture 
The cells were allowed to recover by plating and passaging using the EP propagation protocol before seeding at confluent density for characterization.

\section{Results and discussion}

Independent culture of sieved fractions confirmed that all aggregate pools contributed significantly to the EP precursor pool. A representative plot of the yield from the primary plating of each sieved portion is shown in Figure 1A. The proliferation potential of the $<38 \mu \mathrm{m}$ portion, in which any three-dimensional (3D) stem cell niche would be destroyed, was essentially equivalent to the $38-90 \mu \mathrm{m}$ portion and persisted through continued passaging. Plating density was investigated in four of six isolates and representative results are shown in Figure 1B. Yield/g cortex increased inversely to plating density at primary passage. However, cultures plated at dilutions $>1: 16$ of the standard protocol were subject to an island effect, in which cells become contact inhibited at the centres of islands. For continued expansion, these dilute cultures required passage before the tissue culture medium became depleted. Cells plated at $1.25 \times 10^{6}$ cells $/ 20 \mathrm{ml} / 75 \mathrm{~cm}^{2}$ flask (a concentration calculated from $1: 16$ of a confluent $75 \mathrm{~cm}^{2}$ flask $=2 \times 10^{7}$ cells) required weekly passage, essentially eliminating the need for medium changes between passage days and dramatically decreasing the reagents, supplies, effort and therefore cost of maintenance over more dilute cultures. For the remainder of this report, all assays for identification and efficacy focus on EP cells plated at 1:16 and subcultured at $1.25 \times 10^{6}$ cells $/ 20 \mathrm{ml} / 75 \mathrm{~cm}^{2}$ flask.

In Figure 1C, growth curves of REC progenitors from each donor are plotted as cell yield/g cortex through culture time, along with the average yield from the standard method for comparison. All EP cultures maintained exponential growth for at least 6 weeks, with the exception of the 9 May 2009 isolate, the only one that was terminated due to senescence. The others were terminated because they did not form epithelial monolayers when plated at higher density on tissue culture surfaces. Instead, they had a greater affinity for each other and aggregated into $3 \mathrm{D}$ structures in suspension. Yield exceeded $10^{16}$ cells/g cortex from the only kidney obtained due to an anatomical defect, while the average yield from diseased kidneys was in the range $1.1 \times 10^{9}-8.8 \times 10^{11}$ cells/g cortex, representing an increase of $10.3 \pm 1.4$ doublings over standard methods. Because the cell numbers obtained using the EP methods were sufficient by the time the effect was observed, further propagation and analysis of these cells was not pursued. The plots clearly demonstrate the far greater cell mass obtainable with EP techniques; note the logarithmic scale displayed on the vertical axis (cell yield/g cortex). The cell yields for both methods and relevant donor information are provided in Table 2.

During primary propagation at low density, REC progenitor cells are highly motile, forming adherent islands, floating rafts and non-adherent spheroids (Figure 2A-C). Using standard methods, part of the progenitor pool is discarded as a result of the initial medium change and the non-adherent structures do not have time to form. As cell density increases, the cells coalesce into islands with cuboidal centres and spindle-shaped cells at the outer edges (see Supporting information, Video S1). When plated at higher density with RA for functional testing, the cells quickly develop the familiar cobblestone appearance associated with REC, with occasional doming (Figure 2D, E; see also Supporting information, Video S2). As shown in Figure 3A, advanced EP cultures retained the ability to form polarized epithelium, as evidenced by the formation of apical central cilia, revealed by punctuate AT1 labelling, and the distinctive spider-web pattern of tight junctions was demonstrated with ZO1. The brush border enzymes APN and $\gamma$ GT persisted in advanced EP cultures (Figure 3B, C). The results from the $\gamma$ GT enzyme assay complemented IHC results, with $160 \pm 43$ and $242 \pm 37 \mathrm{U} / \mathrm{mg}$ protein for the standard and EP cells, respectively. No trend was observed as the cultures aged; however, for both populations there was a significant decrease in $\gamma$ GT enzyme activity detected in cells post-cryopreservation, dropping to $78 \pm 14$ and $99 \pm 23 \mathrm{U} / \mathrm{mg}$ protein for the standard and EP cells, respectively (Figure 4A).

Table 2. Relevant donor history and yield

\begin{tabular}{|c|c|c|c|c|c|c|c|c|}
\hline \multirow[b]{2}{*}{ Isolation date } & \multicolumn{3}{|c|}{ Yield cell number/g cortex } & \multirow{2}{*}{$\begin{array}{c}\text { Additional } \\
\text { doublings Fresh/ } \\
\text { CRYO }\end{array}$} & \multirow{2}{*}{$\begin{array}{l}\text { Cause } \\
\text { of } \\
\text { death }\end{array}$} & \multirow{2}{*}{$\begin{array}{l}\text { Age/ } \\
\text { sex }\end{array}$} & \multirow{2}{*}{$\begin{array}{l}\text { Relevant donor } \\
\text { history }^{\mathrm{a}}\end{array}$} & \multirow{2}{*}{$\begin{array}{c}\text { Glomerular } \\
\text { sclerosis }\end{array}$} \\
\hline & Standard & EP & EP-CRYO & & & & & \\
\hline 13 February 2008 & $6.3 \times 10^{7}$ & $9.2 \times 10^{10}$ & $3.0 \times 10^{8}$ & $10.4 / 5.6$ & Anoxia & $57 \mathrm{~F}$ & $\mathrm{D}, \mathrm{HT}, \mathrm{T}, \mathrm{EtOH}, \mathrm{A}$ & $6 \%$ \\
\hline 21 March 2008 & $1.3 \times 10^{7}$ & $3.7 \times 10^{10}$ & $2.7 \times 10^{10}$ & $11.5 / 11.0$ & Trauma & $50 \mathrm{M}$ & HT & $4 \%$ \\
\hline 13 May 2008 & $2.6 \times 10^{7}$ & $9.2 \times 10^{16}$ & $6.3 \times 10^{12}$ & $31.7 / 17.9$ & CVA $^{\mathrm{b}}$ & $65 \mathrm{M}$ & & $0 \%$ \\
\hline 13 September 2008 & $4.3 \times 10^{7}$ & $8.8 \times 10^{11}$ & $2.2 \times 10^{10}$ & $14.3 / 9.0$ & Anoxia & $51 \mathrm{~F}$ & $\mathrm{HT}, \mathrm{T}$, EtOH & $\begin{array}{l}\text { Biopsy not } \\
\text { performed }\end{array}$ \\
\hline 30 October 2008 & $5.3 \times 10^{7}$ & $3.2 \times 10^{10}$ & $6.6 \times 10^{10}$ & $9.2 / 10.3$ & CVA & $52 \mathrm{~F}$ & $\mathrm{D}, \mathrm{HT}, \mathrm{T}, \mathrm{EtOH}, \mathrm{A}$ & $14 \%$ \\
\hline 9 May 2009 & $2.0 \times 10^{7}$ & $1.1 \times 10^{9}$ & Not determined & 5.8/ND & CVA & $78 \mathrm{M}$ & $\mathrm{D}, \mathrm{HT}, \mathrm{T}, \mathrm{RS}$ & $20 \%$ \\
\hline
\end{tabular}

Cell mass generated from enhanced propagation (EP) methods is diminished by cryopreservation (CRYO), but still far exceeds that of the standard protocol. Yield is highly dependent on prior disease state of donor and ranges from $>10^{16}$ cells/g cortex derived from a relatively healthy donor to $<10^{10}$ from a kidney known to be diseased. At a projected cell therapy dose of $10^{8}$ cells, the $13 \mathrm{May} 2008$ donor would yield over $10^{8}$ devices from a single $\mathrm{g}$ of cortex.

${ }^{\mathrm{a} D}$, diabetes; HT, hypertension; T, tobacco use; EtOH, alcohol use; A, asthma; RS, renal stent.

${ }^{\mathrm{b}} \mathrm{CVA}$, cardiovascular accident. 

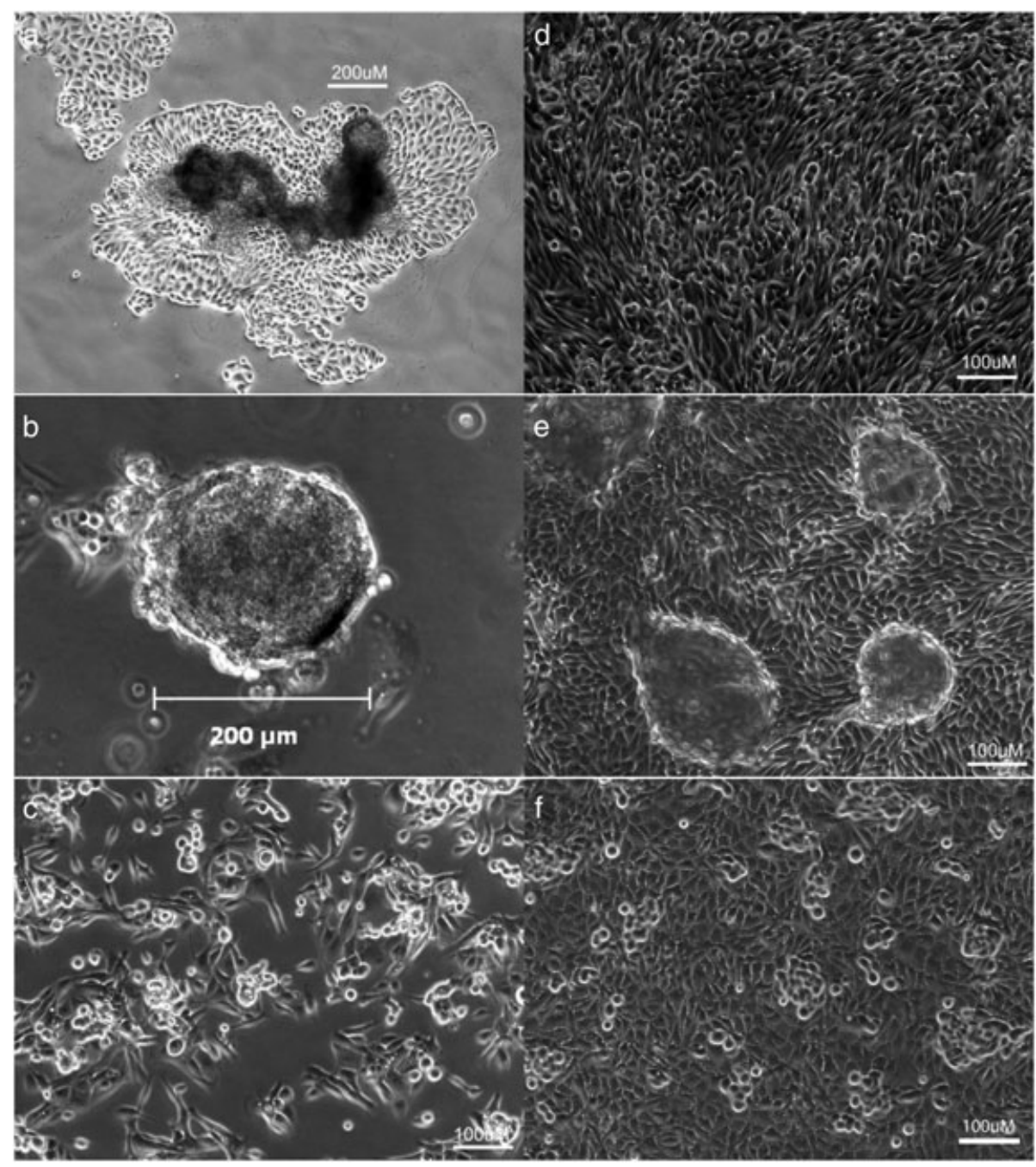

Figure 2. Morphology of REC propagated using the EP protocol. In primary culture REC progenitors form non-adherent floating rafts (A) and hollow spheroids (B), as well as adherent spindle-shaped cells. Post-cryopreservation, progenitor cells kept at low density remain in the exponential growth phase, retaining the spindle-shaped morphology (C). When plated at density with RA, previously cryopreserved cells acquire the cobblestone morphology of differentiated RECs (D), with occasional doming (E). Standard culture at passage 5 is shown for comparison (F)

EP-generated REC retained the ability to respond to endotoxin challenge through advanced culture. LPS stimulated IL8 secretion for all populations tested; however, the amount of IL8 released was highly variable across donors for the standard populations, averaging $6.3 \pm 3.4$ and $17.6 \pm 8.6 \mathrm{ng} / 10^{6}$ cells $/ 24 \mathrm{~h}$ for basal and stimulated, respectively. EP rates were more consistent between donors, with the average being $3.4 \pm 1.1$ and $19.7 \pm 3.5 \mathrm{ng} / 10^{6}$ cells $/ 24 \mathrm{~h}$ for basal and stimulated, and remained within the secretion ranges detected for the standard cultures. The ability to respond to endotoxin challenge persisted through cryopreservation, with basal and stimulated rates being $6.3 \pm 3.4$ and $19.1 \pm 9.6 \mathrm{ng} / 10^{6}$ cells $/ 24 \mathrm{~h}$ for standard and $5.0 \pm 2.1$ and $18.7 \pm 4.2 \mathrm{ng} / 10^{6}$ cells $/ 24 \mathrm{~h}$ for basal and stimulated EP populations (Figure 4B).

Cryopreservation had a detrimental effect on proliferation potential. In addition to a low initial recovery rate of $80 \%\left(8 \times 10^{6}\right.$ viable cells from each vial containing $10^{7}$ cells upon cryopreservation), the overall growth potential was greatly diminished. For the two isolates with the lowest potential, growth rates were unaffected. However, for the isolates having the greatest proliferation potential prior to cryopreservation (13 February 2008, 13 May 2008 and 13 September 2008), the growth potential was reduced between two and four orders of magnitude (Table 2).

Application of EP protocols to human kidneys has significantly increased cell yields compared to the standard method. In aggressively digested kidney cortex, the $<38$ $\mu \mathrm{m}$ fraction, which consists of mostly single cells, still retained a high potential for proliferation, indicating that the retention of a 3D stem cell niche is not a requirement for transient amplification of renal progenitors. Yield was inversely proportional to plating density, while partial medium changes increased yields, indications that more than one factor may be influencing REC progenitor propagation.

Unfortunately, the available kidney pool for REC therapy consists of donors having pre-existing serious health 

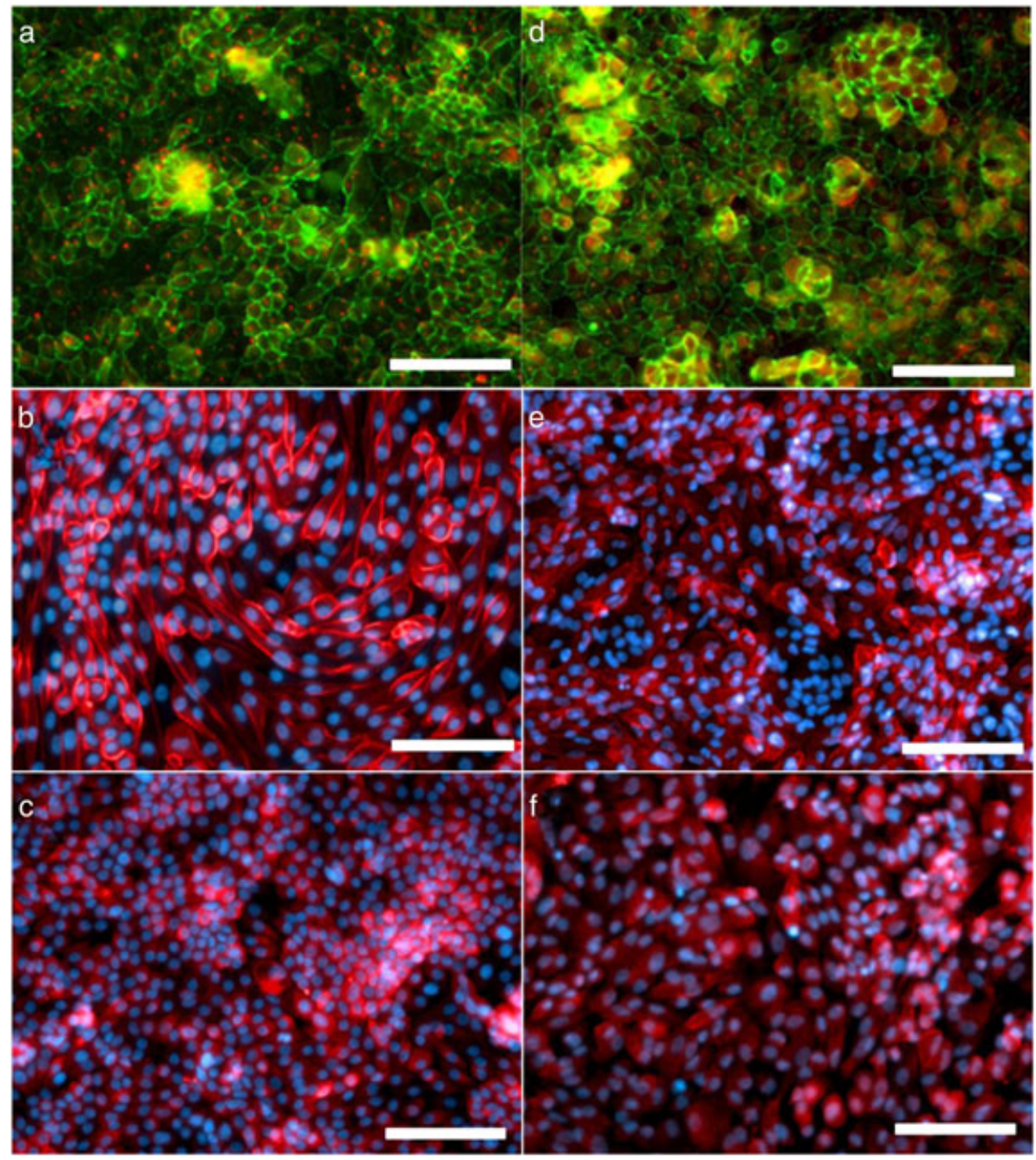

Figure 3. Immunohistochemical comparison of REC propagated using the EP protocol (A-C) compared to the standard protocol (D-F). EP-generated RECs form polarized epthelial monolayers, as demonstrated by acetylated tubulin-positive apical central cilia (red), while zona occludens (green) is concentrated in tight junctions having a distinct spider-web pattern (A, D). Expression of the renal brush border enzymes aminopepsidase N (B, E; red) and $\gamma \mathrm{GT}$ (C, F; red) persists. DAPI counterstaining is shown in (B, E, C; blue).The photographs are representative of advanced EP cultures at yields $>100$ times that possible with the standard protocol, compared to passage 5 standard cultures ( $=$ passage historically used for therapy). Scale bar $=100 \mu \mathrm{m}$
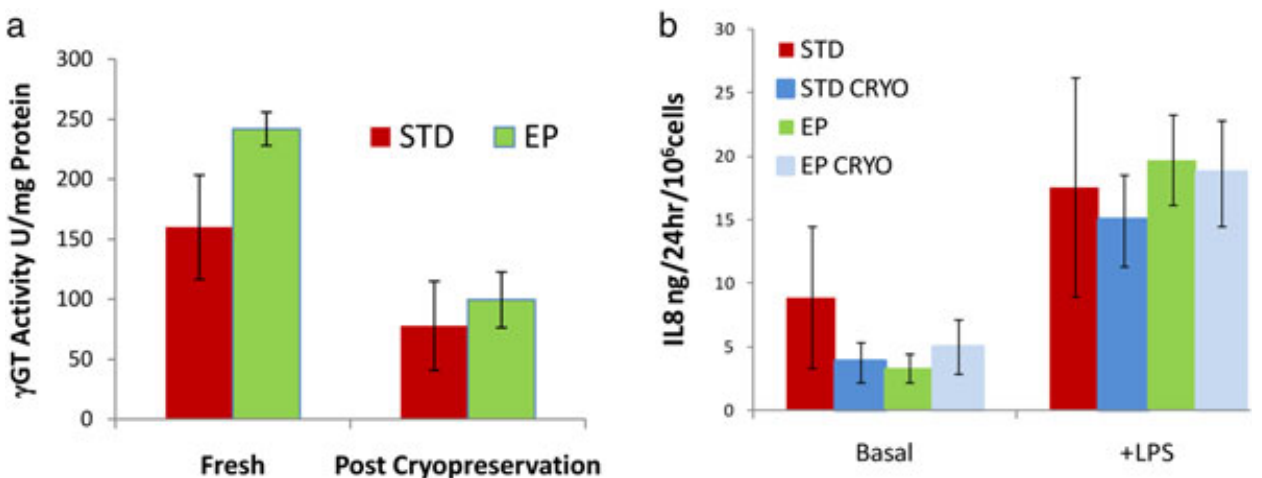

Figure 4. Retention of therapeutic potential through cryopreservation. (A) $\gamma$-Glutamyl transpepsidase ( $\gamma$ GT) enzyme activity was detected in renal epithelial cells generated from both standard (STD) and EP cultures but was greatly diminished post-cryopreservation (CRYO). (B) Addition of lipopolysaccharide (LPS) stimulated IL8 secretion over basal secretion level in all cultures tested and was not affected by cryopreservation. Average results \pm SE for $n=4$ donors are shown

issues, including diabetes, hypertension and sclerosis of the kidney. Although donor health had a large impact on progenitor cell amplification, the post-cryopreservation cell yields from suboptimal donors exceeded $10^{10}$ cells/g cortex while retaining the appropriate morphology and ability to express surrogate efficacy markers. With a 
cell load/device expected to be $10^{8}$ cells, and cortex weight of about $50 \mathrm{~g} /$ kidney, this correlates to more than 5000 devices from a single donor kidney, a vast improvement to the 1-10 devices demonstrated using standard methods. The only kidney donor with no known disease (13 May 2008) yielded over $10^{16}$ cells/g cortex.

With amplification of renal progenitor cells to this magnitude, the EP protocol could be successfully applied to tissue obtained from a kidney biopsy for autologous device manufacture for chronic applications. Kidney biopsies are routinely taken for diagnostic purposes and range from a few milligrams for a needle biopsy to around to $50 \mathrm{mg}$ for a wedge biopsy. If the method was applied successfully to the non-diseased 13 May 2008 isolate, $6.3 \times 10^{12}$ cells, or approximately sixty three thousand autologous devices, could theoretically be manufactured from a $50 \mathrm{mg}$ wedge biopsy. For proof of principle, the EP method was applied to an $11 \mathrm{mg}$ simulated needle biopsy taken from the whole donor kidney prior to dissection on 9 April 2009. Even though the simulated biopsy was from the kidney of the oldest donor with the most pre-existing health issues, and had the lowest overall yield, application of the EP method still yielded enough cells $\left(>10^{8}\right)$ for one autologous renal cell therapy device (data not shown).

To compare cells from standard methods and those generated using the EP protocol, surrogate markers were evaluated in addition to establishing equivalent morphology. LPS-stimulated IL8 secretion and $\gamma$ GT enzyme activity were chosen because they correlate with the ability to respond to inflammation and oxidative stress, mechanisms that are known to be dysregulated in ESRD and correlate with poor outcomes. Additionally, basal IL8 secretion was used as a release criterion for previous clinical trials involving REC (Tumlin et al., 2008). Because the immunoregulatory role of the kidney is very complex and response is highly individualized to the animal or patient (Humes et al., 2003), the usefulness of a surrogate marker panel in relation to actual therapeutic benefit remains unclear. Nevertheless, correlation of in vitro measurements to efficacy will be required for the transition of REC therapy to the clinical setting, and therefore the pursuit of surrogate markers remains a topic of emphasis. Because $\gamma \mathrm{GT}$ enzyme activity and the ability to respond to endotoxin challenge in expanded EP cultures are retained through cryopreservation, these functions provide very promising efficacy markers. EP-derived cells in a bioartificial renal cell system are currently being evaluated using a porcine model of sepsis, where cells are in contact with the ultrafiltate in a haemodialysis circuit. In this model, renal cell therapy with standard cells increased survival time from 6.7 to $11.3 \mathrm{~h}$ (Buffington et al., 2009). Additionally, cells are being evaluated in an ovine model of ESRD, where cell therapy is delivered via peritoneal dialysis (Song et al., 2009). Results from these lines of experimentation will be used to further validate the use of IL8 secretion and $\gamma \mathrm{GT}$ activity as efficacy markers.

The EP method was developed to provide an adequate and reliable supply of functional REC for integration into a cell therapy device. While cryopreservation affected the potential cell yield, only the very basic cryopreservation techniques were employed. Cell function and yield are expected to improve with optimized cryopreservation protocols. Cells derived from EP populations reconstituted post-cryopreservation were successfully integrated into a renal cell therapy device and retained the correct morphology through long-term in vitro maintenance in a perfusion circuit and ex vivo extracorporeal haemodialysis and peritoneal dialysis circuits. Application of the EP protocol to human cadaver kidneys has greatly enhanced cell proliferation, clearly demonstrating a robust cell source for renal cell therapy in two prospective delivery systems.

Emphasis was not placed on understanding the mechanisms responsible for the observed increase in yield. More investigation into the factors influencing REC amplification is merited and may provide further advancement in renal cell progenitor technology, as well as insight into progenitor amplification in other organ systems.

\section{Summary}

As envisioned, application of the EP protocol to human transplant discard kidneys increased cell yield dramatically over the standard method for all six donors tested. The generated cell number from each kidney was highly variable and based on available information, correlated with overall donor health. Yield exceeded $10^{16}$ cells/g cortex from the only kidney obtained due to an anatomical defect, while the average yield from diseased kidneys was in the range $1.1 \times 10^{9}-8.8 \times 10^{11}$ cells $/ g$ cortex, representing an increase of $10.3 \pm 1.4$ doublings over standard methods. Surrogate markers of efficacy, LPS-stimulated IL8 secretion and $\gamma$ GT enzyme activity, were chosen because they represent the ability to respond to endotoxin challenge and oxidative stress. IL8 secretion and $\gamma$ GT activity persisted through advanced EP cultures. Stimulated IL8 secretion was unaffected by cryopreservation, but $\gamma$ GT activity and overall cell yield were significantly reduced. However, the negative effects of cryopreservation may be resolved with the application of more advanced cryopreservation methods. Cells derived from EP populations reconstituted post-cryopreservation were successfully integrated into a renal cell therapy device and retained the correct morphology through long-term in vitro maintenance in a perfusion circuit and ex vivo extracorporeal haemodialysis and peritoneal dialysis circuits. Application of the EP protocol to REC expansion has solved the problem of cell sourcing as the rate-limiting factor to the manufacture of cell-based therapies targeting renal diseases, and may provide a method for autologous device fabrication from core kidney biopsies. 


\section{Acknowledgements}

This work was made possible with NIH-NIDDK SBIR Grant Nos 1R43DK082050-01，1R43DK074289-01，1R43DK074289-02, 1R43DK080529-03, 1R43DK080529-04 and DoD W81XWH-05-201 . We acknowledge the use of human tissues provided by the National Disease Research Interchange (NDRI), with support from NIH Grant No. 5 U42 RR006042-20.

\section{Disclosure statement}

H. D. Humes is a shareholder of Innovative BioTherapies and CytoPherix Inc.

\section{Supporting information on the internet}

The following supporting information may be found in the online version of this article:

Video S1. Adherence and outgrowth of renal epithelial progenitor cells, obtained using Zeiss AxioVision software and $10 \times$ objective ( $1 \mathrm{sec}=40$ minutes).

Video S2. Doming behavior exhibited by differentiated renal epithelial cells, obtained using Zeiss AxioVision software and $10 \times$ objective ( $1 \mathrm{sec}=40$ minutes).

\section{References}

Al-Awqati Q, Oliver JA. 2006; The kidney papilla is a stem cells niche. Stem Cell Rev 2(3): 181-184.

Bates DW, Su L, Yu DT, et al. 2001; Mortality and costs of acute renal failure associated with amphotericin B therapy. Clin Infect Dis 32(5): 686-693.

Bi B, Schmitt R, Israilova M, et al. 2007; Stromal cells protect against acute tubular injury via an endocrine effect. $J \mathrm{Am}$ Soc Nephrol 18(9): 2486-2496.

Bishop GA, Waugh JA, Hall BM. 1988; Expression of HLA antigens on renal tubular cells in culture. Ii. Effect of increased HLA antigen expression on tubular cell stimulation of lymphocyte activation and on their vulnerability to cell-mediated lysis. Transplantation 46(2): 303-310.

Buffington DA, Hageman G, Lou L, et al. 2009; Design of a compact, cryoperservable, bioartificial renal cell system. $J$ Am Soc Nephrol 20: 27A.

Challen GA, Bertoncello I, Deane JA, et al. 2006; Kidney side population reveals multilineage potential and renal functional capacity but also cellular heterogeneity. $J$ Am Soc Nephrol 17(7): 1896-1912.

Chertow GM, Levy EM, Hammermeister KE, et al. 1998; Independent association between acute renal and mortality following cardiac surgery. Am $J$ Med 104: 343-348.

Collins AJ, Kasiske B, Herzog C, et al. 2005; Excerpts from the United States Renal Data System 2004 Annual Data Report: atlas of end-stage renal disease in the United States. Am J Kidney Dis 45(1, suppl 1): A5-7, S1-280.

Cukor D, Cohen SD, Peterson RA, et al. 2007; Psychosocial aspects of chronic disease: ESRD as a paradigmatic illness. J Am Soc Nephrol 18(12): 3042-3055.

Duffield JS, Bonventre JV. 2005; Kidney tubular epithelium is restored without replacement with bone marrow-derived cells during repair after ischemic injury. Kidney Int 68(5): 1956-1961.

Gupta S, Verfaillie C, Chmielewski D, et al. 2002; A role for extrarenal cells in the regeneration following acute renal failure. Kidney Int 62(4): 1285-1290.

Hall PA, Watt FM. 1989; Stem cells): The generation and maintenance of cellular diversity. Development 106(4): 619-633.
Humes HD. 1995; Acute renal failure: prevailing challenges and prospects for the future. Kidney Int Suppl 50: S26-32.

Humes HD. 2000; Bioartificial kidney for full renal replacement therapy. Semin Nephrol 20(1): 71-82.

Humes HD, Fissell WH, Weitzel WF. 2002; The bioartificial kidney in the treatment of acute renal failure. Kidney Int Suppl 80: $121-125$

Humes HD, Weitzel WF, Bartlett RH, et al. 2003; Renal cell therapy is associated with dynamic and individualized responses in patients with acute renal failure. Blood Purif 21(1): 64-71.

Iglehart JK. 1993; The American health care system. Teaching hospitals. $N$ Engl $J$ Med 329(14): 1052-1056.

Imai E, Iwatani H. 2007; The continuing story of renal repair with stem cells. $J$ Am Soc Nephrol 18(9): 2423-2424.

Kale S, Karihaloo A, Clark PR, et al. 2003 ; Bone marrow stem cells contribute to repair of the ischemically injured renal tubule. J Clin Invest 112(1): 42-49.

Krieg AF, Rosenblum LJ, Henry JB. 1967; Lactate dehydrogenase isoenzymes a comparison of pyruvate-to-lactate and lactate-to-pyruvate assays. Clin Chem 13 (3): 196-203.

Leonard M, Ryan MP, Watson AJ, et al. 1999; Role of map kinase pathways in mediating IL-6 production in human primary mesangial and proximal tubular cells. Kidney Int 56(4): 1366-1377.

Potten CS, Loeffler M. 1990; Stem cells: attributes, cycles, spirals, pitfalls and uncertainties. Lessons for and from the crypt. Development 110: 1001-1020.

Poulsom R, Forbes SJ, Hodivala-Dilke K, et al. 2001; Bone marrow contributes to renal parenchymal turnover and regeneration. $J$ Pathol 195(2): 229-235.

Prodjosudjadi W, Gerritsma JS, KlarMohamad N, et al. 1995; Production and cytokine-mediated regulation of monocyte chemoattractant protein-1 by human proximal tubular epithelial cells. Kidney Int 48 (5): 1477-1486

Sagrinati C, Netti GS, Mazzinghi B, et al. 2006; Isolation and characterization of multipotent progenitor cells from the Bowman's capsule of adult human kidneys. $J$ Am Soc Nephrol 17(9): 2443-2456.
Saxen L. 1987; Organogenesis of the Kidney. Cambridge University Press: New York.

Schrier RW, Wang W. 2004; Acute renal failure and sepsis. $N$ Engl $J$ Med 351(2): 159-169.

Smith AM, Potter M, Merchant EB. 1967; Antibody-forming cells in the pronephros of the teleost Lepomis macrochirus. J Immunol 99(5): 876-882.

Smith PL, Buffington DA, Humes HD. 2006; Kidney epithelial cells. Methods Enzymol 419: 194-207.

Song J, Jung J, Ding F, et al. 2009; Uremic animal model of bioartificial renal cell system (BRECS) using continuous flow peritoneal dialysis-based extracorporeal circuit. J Am Soc Nephrol 20: 106A.

Szasz G. 1974; Methods of Enzymatic Analysis. Academic Press: New York.

Tumlin J, Wali R, Williams W, et al. 2008; Efficacy and safety of renal tubule cell therapy for acute renal failure. $J \mathrm{Am}$ Soc Nephrol 19(5): 1034-1040.

Turpen JB, Knudson CM. 1982; Ontogeny of hematopoietic cells in Rana pipiens: precursor cell migration during embryogenesis. Dev Biol 89(1): 138-151.

Van Den Hamer CJ, Elias RW. 1958; A method for the determination of $\mathrm{D}(-)$ lactic acid. Biochim Biophys Acta 29(3): 556-562.

van Kooten C, van der Linde X, Woltman AM, et al. 1999; Synergistic effect of interleukin-1 and CD401 on the activation of human renal tubular epithelial cells. Kidney Int 56(1): 41-51.

Wahl P, Schoop R, Bilic G, et al. 2002; Renal tubular epithelial expression of the costimulatory molecule b7rp-1 inducible costimulator ligand. J Am Soc Nephrol 13(6): 1517-1526.

Wuthrich RP, Glimcher LH, Yui MA, et al. 1990; MHC class ii antigen presentation and tumor necrosis factor in renal tubular epithelial cells. Kidney Int 37(2): 783-792.

Xue JI, Ma JZ, Louis TA, et al. 2001; Forecast of the number of patients with end-stage renal disease in the United States to the year 2010. J Am Soc Nephrol 12: 2753-2758.

Zapata A. 1979; Ultrastructural study of the teleost fish kidney. Dev Comp Immunol 3 (1): 55-65. 